\title{
Analysis of the Efficiency of Applied Virtual Simulation Models and Real Learning Systems in the Process of Education in Mechatronics
}

\author{
Slobodan Aleksandrov ${ }^{1}$, Zoran Jovanović ${ }^{2}$, Dragan Antić ${ }^{2}$, Saša \\ Nikolić $^{2}$, Staniša Perić ${ }^{2}$, Radica Aleksandrov ${ }^{1}$ \\ ${ }^{1}$ Technical School Trstenik \\ Vuka Karadžića 11, 37240 Trstenik, Republic of Serbia \\ ${ }^{2}$ University of Niš, Faculty of Electronic Engineering \\ Department of Control Systems \\ Aleksandra Medvedeva 14, 18000 Niš, Republic of Serbia \\ E-mail: zoran.jovanovic@elfak.ni.ac.rs,dragan.antic@elfak.ni.ac.rs, \\ sasa.s.nikolic@elfak.ni.ac.rs, stanisa.peric@elfak.ni.ac.rs
}

\begin{abstract}
The rapid development of science and technology sets high demands for schools and faculties in terms of educating students to be able to manage complex technological systems. On the other hand, the application of new technologies in modern industry requires the creation of real and virtual laboratories capable of producing the conditions for the rapid and reliable transfer of new knowledge and skills from teachers to students. Having this in mind, the main focus of this paper is the realization of a module as a combination of virtual and real learning systems. The advantage of these systems is reflected in a possibility of creating virtual laboratories using three-dimensional models that simulate real industrial systems. Research shows that the use of virtual didactic systems in modern education increases motivation for learning, reduces learning time and enables modelling and simulation of real systems. However, in order to improve professional competencies, an interaction of simulation models with real industrial systems is needed.
\end{abstract}

Keywords: Mechatronics; education; learning systems; real and virtual laboratory; simulation

\section{Introduction}

Education in the field of mechatronics is a rather complex teaching process and requires the use of modern teaching methods and modern learning systems [1]. The term mechatronics is defined by Tetsura Mori: "The word, mechatronics, is 
composed of 'mecha' from mechanism and the 'tronics' from electronics. That is to say technologies and developed products will now incorporate electronics more intimately and organically into mechanisms, making it impossible to tell where one ends and the other begins" [2]. With the development of microprocessor technology and its application in the control of electro-mechanical systems, the original definition of mechatronics evolved, so Harashima, Tomizuka and Fukada, defined Mechatronics as: "The synergistic integration of mechanical engineering, with electronics and intelligent computer control in design and manufacturing of industrial products and processes" [2]. Despite efforts, there is still no definition that completely covers the meaning and application of mechatronics.

For successful education in mechatronics, modern learning systems are needed, ones which correlate with real industrial mechatronics systems [3]. These learning systems are characterized by modularization, flexibility, re-programmability and software support for modelling, simulation and networking. To enable students to be capable of applying acquired theoretical knowledge and practical skills to real industrial systems [4], these modern learning systems have to be realised with industrial components.

Many papers try to explore an alternate approach which employs simulation to the real industrial production equipment in learning control technology [5]-[8]. Software tools such as MatLab, LabView, Cosimir Robotics, Cosimir PLC, etc., are used to model and simulate the behaviour of real practice/didactic scenarios. A variety of learning environments implemented and tested in the publication "Mechatronics training in real and virtual environments" is one of the outputs from Marvel, a pilot project under the "Leonardo da Vinci" action programme for implementation of the European Community's vocational training policy. The main target groups for Marvel were students, trainees and instructors in vocational education and training [9], [10]. Simulation can be used to reduce the amount of time that students have to spend on executing real experiments [11], [12]. It is obvious that computers have to be used as tools to provide alternative source of learning material, but computer simulation cannot replace all forms of applied training [13], [14].

It is very common in teaching that the application of software solutions for simulation and modelling are potentiated, wherein the use of real learning systems is neglected. As a result of insufficient practice with real learning systems, after schooling, we get personnel that need additional training in working with industrial systems. On the other hand, the use of the real learning systems exclusively is limited by the small number of students that can be trained at the same time and a certain number of different learning systems and high education price. In order to make the teaching process challenging, stimulating and efficient, it is desirable to use modern software and hardware learning systems. In this way, the price is reduced, the number of participants in a group, trained simultaneously, is increased and different dynamics of knowledge and skills acquisition, according to the potential and desires of students, is enabled. 
The new concept of education in this field should link theoretical knowledge and practical skills. In this way, these learning laboratories will enable students to design, control, test, and maintain existing and new mechatronics systems. A virtual environment created in this manner should enable students to respond to the future requirements of industrial mechatronics systems. On the other hand, these learning systems are characterized by rather high prices, so it is difficult for schools and faculties in our surroundings to provide sufficient number of different learning systems.

The goal of the research presented in this paper was aimed at the significance of the application of real and virtual learning systems in the teaching process of secondary vocational school of educational profile Technician of mechatronicspilot program. The survey was carried out with the help of professors from the Faculty of Electronic Engineering in Niš. The aim of this cooperation is to establish the continual educational process, creating new teaching plans and programmes, based on the knowledge and skills that future students have acquired during previous schooling. The main advantage of this research is the fact that the two generations of students of the final year, from four different schools, have taken part in the survey. These four schools have exactly the same equipment, so the conditions for knowledge and skills acquisition are the same in all the schools. It must be highlighted that any other factors (social status of the student's family, the amount of time allotted to and needed for learning etc.) [1] which affect the teaching process and students are not taken into consideration in this step of the research. After the module was finished, based on their experiences in working with real and virtual systems, they evaluated the efficiency of the method of knowledge transfer.

This paper is organized as follows. In Section 2, we present the detailed description of the module. The short descriptions of real learning systems, used in the realization of this module, are presented in Section 3. In Section 4, a 3D simulation tool for practical PLC training, Cosimir PLC, is described. Cosimir Robotics, the leading 3D robot simulation system, is described in Section 5, and in Section 6, the survey is described and the obtained results are presented and discussed. In the last section, we give concluding remarks and future works.

\section{Detailed Course Description}

The curriculum of the module, Testing and diagnostics of mechatronics systems, is rather complex. In order to adopt the defined knowledge and skills covered by the teaching plan and program, previous knowledge of pneumatics, sensors, electric motors, microcontrollers and PLC is needed. The module is divided into three logical units. Sixty classes are assigned for the first part of the course. 
In the introductory part, the students are divided into teams and acquainted with real mechatronics system in the mechatronics cabinet. The first mechatronics system is the Festo MPS Distribution Station. The students are familiarized with the procedure for linking a mechatronics system to a computer, installing the required software and transferring the program from a computer to PLC station for distribution. Next, the station is put into operation and the algorithm of functioning of the mechatronics system is monitored. After the demonstration, each of the teams repeats the procedure of demonstration. Every member of a team fulfills certain procedures on their own. There is only one distribution station in the mechatronics cabinet, so the other teams are familiarized with electric and pneumatic scheme, sensors and actuators, in the meantime. Five school classes are assigned for this exercise (E1) and for each of the following exercises.

The second exercise (E2) is an introduction to the software for 3D modelling and simulation, Cosimir PLC. This program allows for individual work of students, getting to know all components of the system, simulation of functioning of mechatronics system and monitoring the state of sensors and actuators. With the use of virtual models, it is possible for every student to acquire knowledge and skills on the computer on his own, with the desired dynamics.

In the third exercise (E3), the professor simulates various faults on the virtual model of Distribution station, and the students test virtual models, detect faults and remove the causes of faults. When a student completely masters the software packages for simulation, he is ready to safely use real the mechatronics system.

The fourth exercise (E4) involves working on a real system for distribution, the detection of electrical, mechanical and pneumatic components, installation and reinstallation, and conducting electric and pneumatic wiring. The fifth exercise (E5) involves the detection and removal of mechanical faults and faults on pneumatic installation and components. The sixth exercise (E6) involves the detection and removal of faults on electric and electronic components. Students prepare reports in electronic form for each of the exercises. Training for the mechatronics system MPS Sorting station is realised in the same way as training for Distribution station (E7-E12).

The second logical unit is training on the MPS Robotic system. For this part, 60 classes are assigned (E13-E24). During the first exercise, students are acquainted with a real industrial robot, the Mitsubishi $R V-2 A J$, and the control of robot is demonstrated (manual, computer control and automatic mode).

That is followed by a short course in programming a robot in programming language Melfa Basic IV, learning about a software for the 3D modelling and simulation of Cosimir Robotics, writing and testing programs in virtual environment and, at the end, the simulation and detection of fault in 3D environment (E14-E17). 
In exercises E18-E22 students program and test the program in the programming environment Robot Explorer and transfer the program in robot controller and monitor functioning of industrial robot. In E23 and E24, students simulate faults on the industrial robot, and the faults are detected and removed.

In the third logical unit (35 classes) students perform synchronisation of functioning of Robot station, Distributing station and Sorting station (E25). They simulate and detect faults on the formed technological process (E26, E27), network mechatronics systems in LAN (E28), monitor system parameters and control mechatronics systems through LAN and WAN network (E29) and create SCADA system (E30, E31).

\section{Description of Experimental Framework}

As we mentioned before, the fast development of modern control systems for industrial processes requires modern learning systems, which, in their construction and characteristics include real industrial systems [15]-[17]. Modern learning systems make it possible for students to apply acquired theoretical knowledge on real systems, to get to know industrial pneumatic, electric and electronic components, hardware structures and programming of PLC, monitoring and adjusting of system parameters, and the principles of the functioning of complex mechatronics systems. Combining several such systems, a unique complex system can be created that fully simulates a real industrial process. Getting to know the characteristics and kinds of sensors, mechanical modules, programming industrial computers and controlling actuators on industrial systems presents the basis for education in the field of mechatronics.

In the mechatronics cabinet in the Technical school Trstenik, Serbia, we use learning systems which belong to the Festo modular production line MPS (Modular Production System) [18]. Many technologies are integrated to make these sophisticated production systems: mechanical, electrical, electronics and software. The main feature of these systems is that they represent real industrial systems that are realised with industrial components and are managed by industrial PLCs. The laboratory framework is equipped with Robot station Mitsubishi Melfa RV-2AJ, Distribution station and Sorting station (see Fig. 1) learning systems. These systems are supported by software for programming the PLC and robots, software for communication and software for 3D modelling simulation.

The first learning system, the Mitsubishi Melfa $R V-2 A J$, is a robotic hand with five degrees of freedom. Robot control is performed via the controller CR1-571. The controller has a modern 64-bit RISC/DSP processor (CPU), which allows simultaneous control of up to 6 axes. All sensors and actuators of the robot are connected to the controller. The robot controller via serial link RS232c is 
connected to a PC. The basic functions of the controller are: indirect interpolation, direct interpolation, 3D interpolation, palletization, subroutines, multi-tasking, conditional branching, speed control and optimal route connection. The joints of the robot are driven by AC servomotors, while the actuator is a pneumatic grip having photo sensors. Thanks to this learning system the students should be able to master hardware structure of the system, the interaction, control and programming of real industrial robots.

Learning systems for distribution and sorting, which are controlled by the PLC, are used to program, test and diagnose real mechatronic systems. These systems are controlled by Festo PLCs FC640 which have a network module and support for TCP/IP and which are directly connected to a local switch device by Ethernet cable. Each PLC has a unique IP address, thus enabling direct access through the computer network. The Distribution station separates work pieces from the storing place. The fill level of the storing place is checked by a one-way light barrier. A double-acting cylinder pushes work pieces out individually. The charger module grips the separated piece with vacuum gripper. Driven by a rotary drive, the arm of charger moves the work piece to transfer point on conveyor of the Sorting station. When diffuse sensor detects the work piece, conveyor is started and the stopper is activated. Sensors in the front of the stopper detect the work piece characteristics (black, red or metal). The work pieces are stored in the appropriate slides via sorting gates that are moved by short-stroke cylinders via diverting mechanism. A through-beam sensor monitors the filling level of the slides. The main advantage of these systems is reflected in their modularity; i.e. the funcional moduls, sensors and algorithms can be changed.

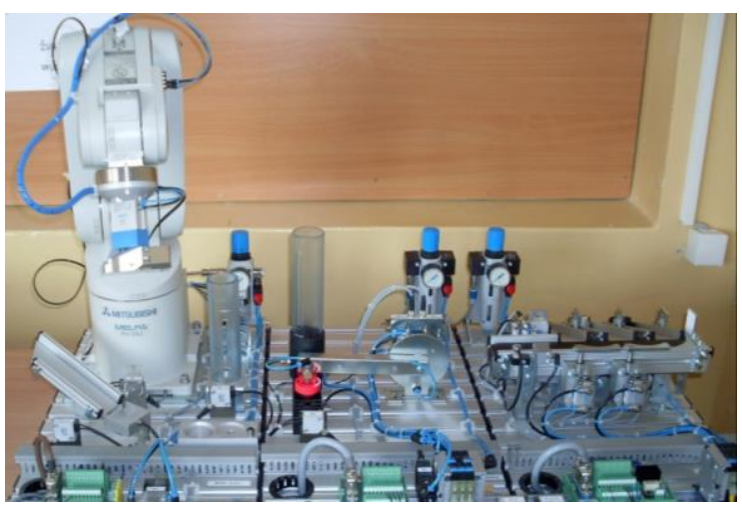

Figure 1

Experimental framework

It can be noticed that real learning systems are suitable for testing, diagnosing and servicing mechatronics systems because they enable hardware and software simulation of faults. However, the main shortcoming is that a maximum of three students can be trained on the same education system at the same time. Such 
systems for training have a relatively high price for most schools and faculties in the surroundings, so educational institutions are not able to own a larger number of the same educational systems on which simultaneous training could be held.

The alternative to the classical approach is to use virtual simulation learning systems, which simulate the functioning of real systems on a computer. Training is held on computers where programs for modelling and simulation are installed. In this way, a student can acquire the basic knowledge on their own, and, at the same time, groups from 10 to 20 members can be trained simultaneously.

\section{Cosimir PLC Software}

Nowadays, the use of the programmable logic device (PLD) and the programmable logic controller (PLC) is pervasive in educational and industrial applications [19]. It is already proved that the use of industrial units PLD and PLC can contribute to the student learning experience [20], [21]. Festo MPS mechatronics systems use the PLC of manufacturers known worldwide, like Festo, Siemens, Mitsubishi and Allen-Bradley, for controlling. In this paper, we present educational systems controlled by Festo PLC FC640. For realistic threedimensional simulation of PLC system, the appropriate software Cosimir PLC is used.

Cosimir PLC represents a 3D simulation tool for practical PLC training. This virtual three-dimensional environment enables individual graphic work surroundings for each student. These software tools create an inspiring and stimulating work environment for the acquisition of new technologies. The basic characteristic of this software is that it possesses a library with finished models identical to the physical learning systems of the Festo MPS series. The procedure of starting, resetting and stopping the station fully corresponds to real systems. The software enables comfortable work, without the possibility of causing damage to the real system. Cosimir PLC does not require special hardware resources; therefore, all computers of the Pentium IV generation can be used. The newer version of this software is called the Ciros Automation Suite, but, for its optimal functioning, a computer of great processing power and with powerful graphics card and memory support is needed, which requires additional cost that is not small.

Virtual three-dimensional simulation represents real system with the only difference that control is performed by pressing a mouse taster on the model instead of the taster on the control panel. Simultaneously with the loading of three-dimensional model of mechatronics system, the corresponding program of the PLC that controls the functioning of chosen station is loaded. The work environment of the Cosimir PLC with the model of the distribution station is presented in Fig. 2. 


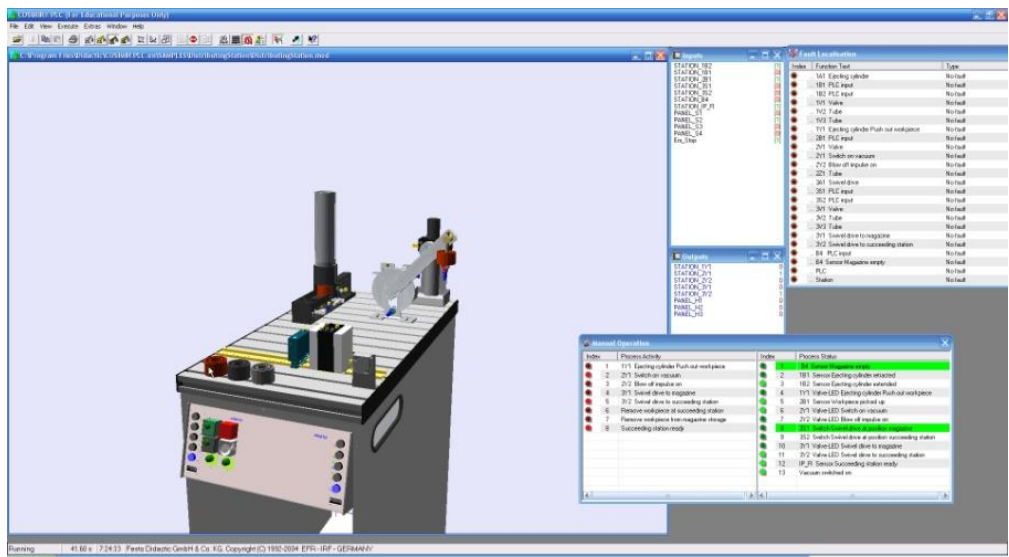

Figure 2

Virtual three-dimensional learning system - MPS distribution station

There are also separate windows with statements of input and output of PLC on the desktop of the monitor. Starting the simulation, the values of input and output are changed according to the algorithm of functioning, and this change is shown in windows Inputs and Outputs. Monitoring of the sensors and actuators state, at any time, is performed by activating a special mode of this software, Step by Step. Monitoring and analysis of a system is possible only if the system is divided into modules, based on structure of control, mechanical configuration, electric motor drive, electric and electronic components, generator of signals and energy flow. In Table 1, the function modules that make up a structure of learning systems, together with their basic characteristics, are presented.

Table 1

Function modules and characteristics of real learning systems

\begin{tabular}{|l|l|l|}
\hline No. & Function modules & Components, parts, programme, functions \\
\hline $\mathbf{1}$ & $\begin{array}{l}\text { Structure of system and } \\
\text { control structure }\end{array}$ & $\begin{array}{l}\text { Program flow chart, graphic diagram, functional } \\
\text { diagram and system description }\end{array}$ \\
\hline $\mathbf{2}$ & Mechanic configuration & $\begin{array}{l}\text { Mounting and adjusting the mechanical parts, } \\
\text { function mechanical modules }\end{array}$ \\
\hline $\mathbf{3}$ & Drives & Electric, pneumatic, hydraulic, mechanical \\
\hline $\mathbf{4}$ & Controlling elements & Electric, pneumatic, hydraulic, mechanical \\
\hline $\mathbf{5}$ & Control system & $\begin{array}{l}\text { Electrical relays, PLC, CNC, pneumatics, robot } \\
\text { controllers }\end{array}$ \\
\hline $\mathbf{6}$ & Generators of signals & Binary sensors, analogue sensors, digital sensors \\
\hline $\mathbf{7}$ & Power supply & Electric, pneumatic, hydraulic \\
\hline
\end{tabular}

One of the most significant options of this software package is the possibility for simulation of a system fault. The process of fault simulation is performed in protected mode (Teacher mode), and to get to this function a password is needed. 
A teacher chooses one or more faults from the range of possible system faults, such as the disconnection of the power supply, a sensor failure, a component missing, a fault in pneumatic installation, etc. Along with the choice of a fault, it is possible to define the duration of the fault as well as the time of its activation in the system. After the fault is set, we leave Teacher mode environment in order activate the fault. In order to test and diagnose the fault, there is a specific part of the program for fault detection - Fault Localisation. Using this command, we localise the fault, remove it and exit this part of program. The removed faults are marked with a green line, and the faults that are still active with a red line. All the system faults, with their type and time of appearance, are archived in a separate fault file (Fault $\log$ ). These data can be reviewed and analysed after the simulation. After the fault has been removed, it is possible to start the system simulation.

The procedure of fault simulation is similar on real learning systems. The addresses of input and output variables are the same, and the marking, appearance and position of system components are identical. Before real or virtual models are started, it is necessary to reset the system, i.e., to set initial conditions. To start a certain actuator, its respective sensors have to be active, as do all the states of all sensors relevant for that actuator change. This part of program enables monitoring process activity and states of all sensors and actuators. During the simulation of system, the statuses of input and output in PLC change, which is visually presented in the Manual operation window. There is a possibility to activate each of the actuators separately and in that way to monitor the status of signals which it activates or deactivates. In order to start this option, the simulation of system has to be closed. Thus, the system can be monitored every step of the way, which facilitates the learning process. This way of functioning corresponds to the manual mode of a real system, when a PLC program is executed step by step.

In this way, it is possible for students to become familiar with the basic components of mechatronics systems, monitor the algorithms of system functioning, program and test the PLC, simulate faults of a system, and detect and remove a fault. Using simulation software, students adopt much faster the principles of the functioning of a mechatronics system, as well as monitoring of system parameters and the statuses of input and output values on the mechatronics system.

\section{Cosimir Robotics Software}

A robot controller connected to a computer with serial link RS232 controls the robotic station. The robotic station is a part of the Festo MPS system, on which the industrial robot, Mitsubishi RV2AJ, with supporting work environment is set. 
Due to specifics in controlling and programming the robot, the software development environment for programming and simulation, Cosimir Robotics, is used for this system. This software provides a virtual work environment for education in the field of robotics and automation. Attending the classes, the students have used the software for the simulation, testing and diagnostics of mechatronics systems in a virtual environment. Using this program, programs for the simulation of functioning of mechatronics systems can be created, and also, existing examples which are delivered with MPS systems can be used. We used the Cosimir Robotics toolbox for the programming and simulation of robot functioning. Mostly every school and faculty try to provide as many education systems (a minimum of three) as possible in order to create the conditions for learning a wide range of knowledge and skills. A virtual three-dimensional environment for real system simulation contains a library of models of real components, with the same labels, and it behaves as a real industrial system. The virtual system is intended for creating 3D models of robotic and flexible production systems, their programming and real operation simulation (see Fig. 3).

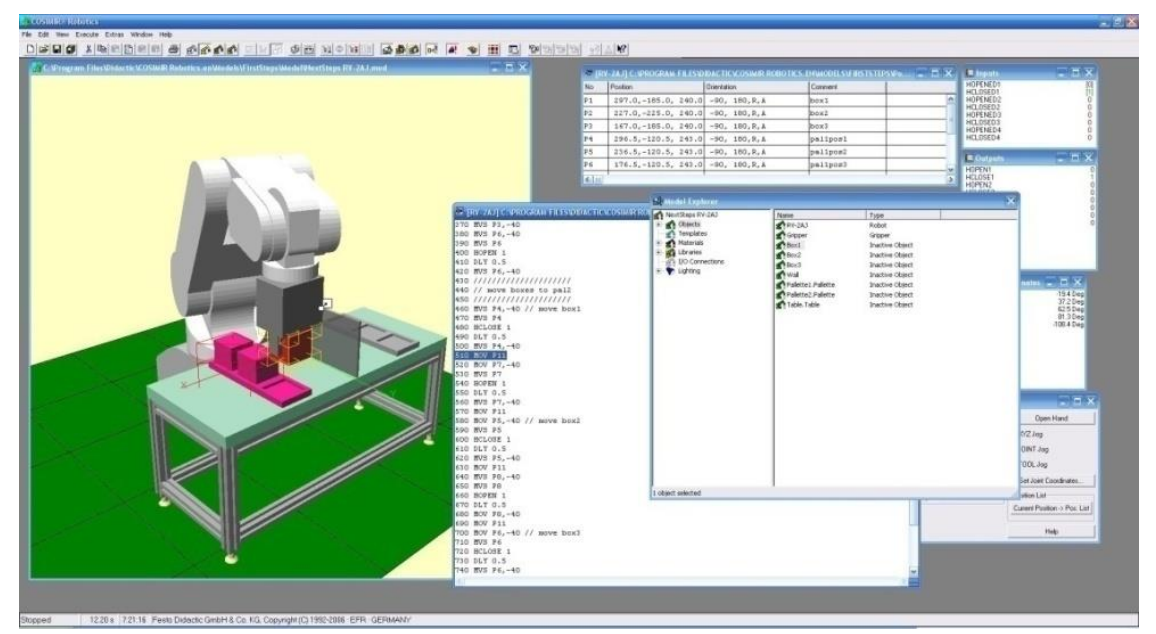

Figure 3

Virtual robot environment - 3D model Mitsubishi RV2AJ

This facilitates planning, programming and testing of robots in every defined position, primarily in the $3 \mathrm{D}$ environment, and then in a real system. With this system, all sequences of moving, gripping and transferring are simulated, trajectory and time cycle is optimised, and elimination of collision is performed. The virtual environment is created by choosing an already-defined components library, such as machines, tools, warehouses, robots and other components.

The Cosimir Robotics software is based on the principle of an open approach to learning, which is characterised by constructive approach to learning; all models and tools are available and can be combined and used according to the 
individual's needs and the learning goals. This software is supported by multimedia system for providing help, Robotics Assistant, which contains textual description of robotic system, models, examples, a graphical presentation, as well as video material and animations. A very significant characteristic of this system is that three-dimensional virtual robot with its construction, components and functioning completely corresponds to a real industrial robot. The virtual environment enables defining the coordinate points through which the robot will pass, writing programs, compiling and simulation. Programs are tested in virtual the 3D environment, which enables students to monitor the program and motion of robot simultaneously. Thus, the effects of each command are visible and faults are easily detected. This system allows for different levels of knowledge and skills acquisition and promotes new methods of research, discovering and projecting. Using virtual models, students attain the basic knowledge and skills for working with real models. They come across problems when a designed system does not function. Faults can be detected independently, and it is possible to improve the efficiency of system functioning and to create more complex systems on the grounds of initial basic model. Cosimir Robotics enables monitoring tools coordinates, choosing the coordinate system, programming, testing the program functioning, and simulating the robot functioning in a $3 \mathrm{D}$ environment. Programming and controlling industrial robot RV2AJ is much easier, faster and safer, when students acquire the basic knowledge and skills using the simulation model.

It is very important to highlight that software packages for 3D simulation cannot replace real education systems, but they may facilitate and speed up the process of acquiring knowledge and skills, which will be confirmed in the conducted survey, presented in following section.

\section{Survey Description and Analysis of Results}

In order to verify the proposed teaching method, presented in this paper, an anonymous survey was conducted in four schools that have exactly the same conditions for realising the teaching process. The target group were the students of the first and second generation of the fourth year of technician of mechatronics. In the school year 2010/2011, 84 students (group A) were involved in the research, while in the school year 2011/2012, 102 students (group B) were involved. Each of the schools is equipped with the mentioned education systems and supporting software for virtual simulation in their mechatronics cabinets. This model of learning stimulates students to master very complex mechatronics systems in a modern, prompt and efficient way [9], [10], [22], [23].

In the course of implementing the new methods of learning and the new software and hardware tools, experts in the fields of pedagogy and psychology were 
consulted. The monitoring of the application of new methods and means of teaching is sporadic, so it often happens that new models are age-inappropriate, too complex, or inapplicable at all levels of learning. Since the student is at the centre of educational process, the way they accept new learning systems and the results they achieve in their application are very important.

The goal of this research is to get relevant information from the students about efficiency of virtual and real learning systems in mechatronics teaching. Based on these results, we can define certain contents which are adopted using virtual software for simulation, practical skills which must be adopted using real learning systems and record software models that do not give the desired results.

The students gave answers to the questions from Table 2 in the following way:

- Score 1 - Strongly disagree,

- Score 2 - Disagree,

- Score 3 - Neutral,

- Score 4-Agree,

- $\quad$ Score 5 - Strongly agree.

Table 2

Survey statements used to assess learning performance

\begin{tabular}{|c|l|}
\hline $\mathbf{1}$ & \multicolumn{1}{|c|}{ Statement } \\
\hline $\mathbf{2}$ & $\begin{array}{l}\text { The use of software for modelling and simulation is needed for } \\
\text { successful knowledge and skills acquisition. }\end{array}$ \\
\hline $\mathbf{3}$ & $\begin{array}{l}\text { Software for simulation, Cosimir PLC and Cosimir Robotics, are } \\
\text { interesting and challenging for students. }\end{array}$ \\
\hline $\mathbf{4}$ \\
$\begin{array}{l}\text { Software for simulation, Cosimir PLC and Cosimir Robotics, are } \\
\text { systems. }\end{array}$ \\
\hline $\mathbf{5}$ & $\begin{array}{l}\text { Software for simulation, Cosimir PLC and Cosimir Robotics, are } \\
\text { suitable for the simulation and detection of faults on mechatronics } \\
\text { systems. }\end{array}$ \\
\hline $\mathbf{6}$ & $\begin{array}{l}\text { Software for simulation, Cosimir PLC and Cosimir Robotics, cannot } \\
\text { fully replace real learning systems. }\end{array}$ \\
$\begin{array}{l}\text { Software for simulation, Cosimir PLC and Cosimir Robotics, in } \\
\text { combination with real learning systems are the best approach for the } \\
\text { process of learning. }\end{array}$ \\
\hline $\mathbf{7}$ & $\begin{array}{l}\text { Software for simulation, Cosimir PLC and Cosimir Robotics, are easy } \\
\text { to learn. }\end{array}$ \\
\hline $\mathbf{8}$ & $\begin{array}{l}\text { Training on real systems is easier if software for 3D modelling is used } \\
\text { previously. }\end{array}$ \\
\hline $\mathbf{9}$ & $\begin{array}{l}\text { Software for simulation lessens the possibility of damaging real } \\
\text { mechatronics systems. }\end{array}$ \\
\hline $\mathbf{1 0}$ & $\begin{array}{l}\text { Software for simulation reduces the student's fear of complex real } \\
\text { mechatronics systems. }\end{array}$ \\
\hline
\end{tabular}


Graphical representation of average score to any question from Table 2 is shown in Figure 4. These results give us the opportunity to analyse the application of education system in the school years 2010/2011 and 2011/2012, respectively.

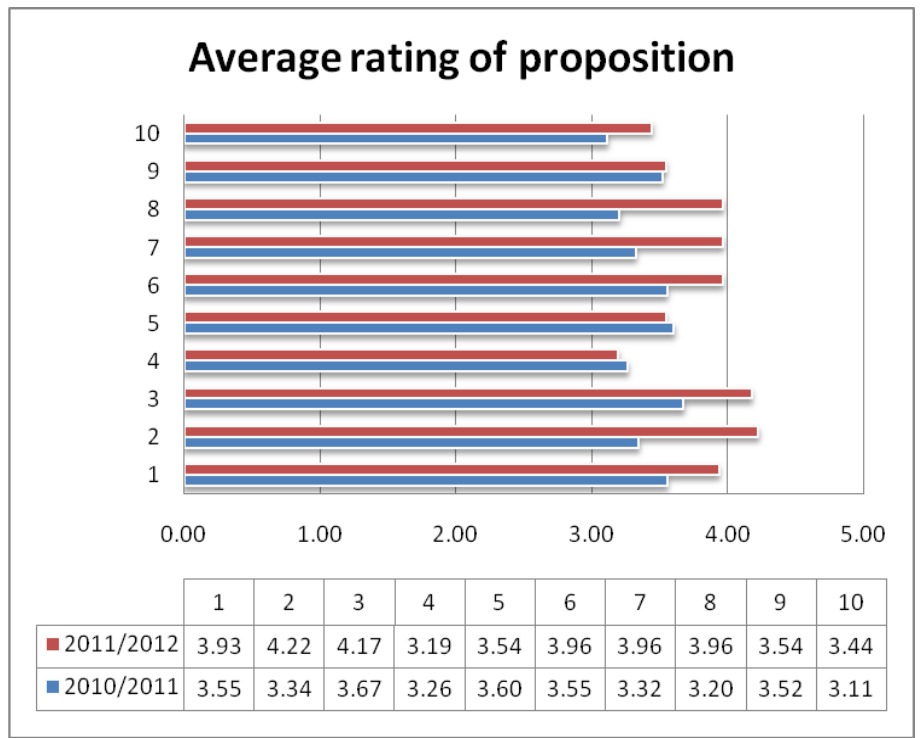

Figure 4

Graphic representation average rating of proposition in school years 2010/2011 and 2011/2012

To analyse the research, it is necessary to see also the results students have achieved at the end of their schooling. At their final examination, students took a test of vocational-theoretical knowledge and final practical work. The average score on the test of vocational-theoretical knowledge was 3.28, and the average score on the final practical work was 4.60. The average score on both practical and theoretical parts was 3.62. If we compare this score with average scores at all statements in the survey, we can see that deviation is very small. Experience in teaching practice has shown that students with better academic accomplishments have a wider range of interests and great knowledge in computers and programming and easily adopt and implement new methods and new means of teaching. Students with less knowledge mainly focus on work with real industrial systems. Percentagewise, the scores according to question is shown in Figs. 5 and 6. 


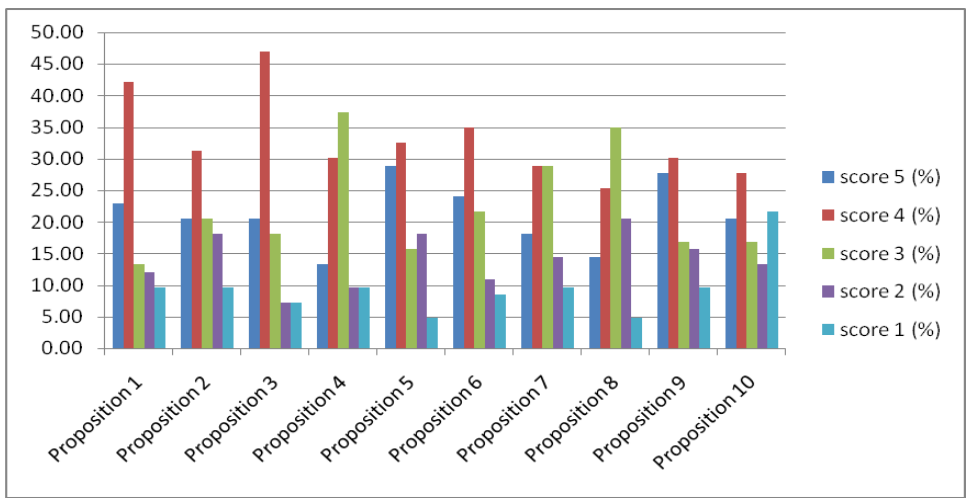

Figure 5

Percentagewise scores representation in 2010/2011

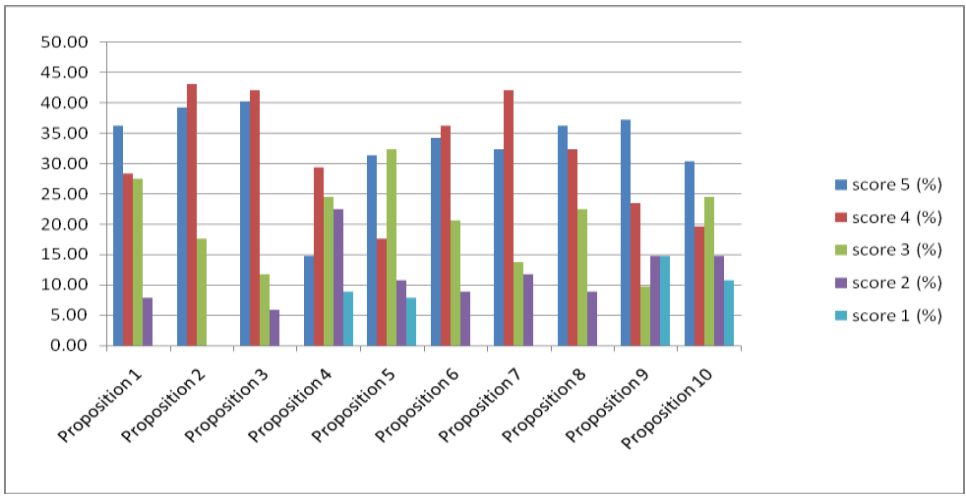

Figure 6

Percentagewise scores representation in 2011/2012

Comparing the results, for group A (2011) and group B (2012), from Figs. 5 and 6 , we have the following analysis:

- The students point out that the use of simulation models in the teaching process is very necessary (65\% for both groups), while $8 \%$ of students of group B do not accept the use of these models, significantly less in comparison to $22 \%$ of students of group A. This result suggests that the students of group B posess much more knowledge in the area of information and computer technology, and they willingly accept participation in this teaching method.

- In group B, $82 \%$ of students believe that the use of virtual models increases learning motivation. This high percentage, in comparison to the first group, can be justified by the fact that students are satisfied with the teaching method, and one of the reasons could be the possibility that the 
students performed the assignments on their own. It should be noted that teachers have feedback results from the previous generation, and they now improved their teaching process.

- In addition, both groups of students believe that the use of virtual models in testing and diagnostics is necessary (44\%). However, this rather small percentage suggests that students have not yet fully mastered the teaching material and they are not prepared to use the acquired knowledge on their own.

- Students of group B claim that virtual models are easier to learn (75\%:47\%) and therefore they have much more involvement in the learning process (69\%:40\%), which indicates that the second generation of students more easily accept the new software tools and that they are ready to use the new technologies for improving their knowledge.

- A high percentage $(61 \%)$ of students of group A believe that virtual models cannot replace the real system in the learning process, while this percentage is significantly reduced in group B (49\%), which indicates that the second generation of students recognizes the importance of combining virtual simulation models with real learning systems, which can be very helpful for solving practical problems in the future.

- The confirmation of the good teaching approach comes from the high percentage of students of both groups who believe that it is necessary to combine virtual and real learning systems. This percentage is $10 \%$ higher in group B, which shows that for the successful acquisition of knowledge and skills in the areas of technology, it is necessary to combine virtual and real didactic components and systems.

It must be highlighted that many other factors could affect the survey results, but they were not taken into consideration for this research. These factors are, for example, the various psychological orientations, general learning abilities (the ability of self-regulated learning), and the degree of comprehension (general intelligence, verbal skills), as well as several environmental factors, etc. [1].

Having in mind the results of the research, we can say that a large majority of students use virtual models in combination with real learning systems. The application of simulation models has a special significance in the hybrid model of learning, that is to say, in combination with training on real learning systems and industrial systems. The significance of application of software for simulation and modelling of mechatronics systems is in the fact that it:

- allows knowledge and skills acquisition in a modern and fun way,

- allows independent learning in preferred dynamics,

- allows a large number of repetitions of the same procedures,

- speeds up the process of learning,

- increasing motivation for learning,

- reduces the cost of education, 
- reduces the fear of using real components and systems,

- prepares the students for working with real components and systems,

- allows working with a large number of different mechatronics systems.

Software for virtual learning, despite its great characteristics, does not represent replacement for real learning systems, but is a powerful software platform which facilitates and accelerates the process of knowledge and skill acquisition. The fusion of theoretical knowledge, practical skills and virtual 3D models represents a model for education in the field of mechatronics that has given great results in the education of technicians of mechatronics.

\section{Conclusions and Future Works}

In this paper, we have presented a hybrid learning model using real and virtual learning environment in the field of mechatronics. This learning method is applied in the teaching process of secondary vocational school of educational profile for the technicians of mechatronics pilot program in Trstenik, Serbia.

Simulations of processes can be used to familiarize students with all the components and units of modern mechatronics systems, in an interesting and modern way. Moreover, they have a significant role in modelling and testing systems, in cases where work on real systems is dangerous or very expensive. In this way, students can create and test desired models on their own and analyse the results of their work. The results of students' programming, testing and diagnostics are immediately visible, which gives great stimulation for further learning and exploring. There is no danger of student injury or damage to the system in a virtual environment, so various models of real systems can be simulated, tested and diagnosed.

However, to achieve the desired level of professional competencies, based on our experiences and the survey conducted in this paper, the best approach is to combine virtual models with real industrial systems. In that way, students are able to apply the acquired theoretical knowledge on real systems, which will decrease the fear of working with these kinds of real industrial systems in the future. Also, the possibility of injury during the work with real systems is reduced to a minimum, and the motivation for learning is raised to a higher level.

The main shortcoming of this learning method is that virtual and real learning systems are available for students at fixed intervals. In our future work, we will solve this problem by forming a system for remote access to the learning systems in mechatronics cabinet using video cameras, high-speed internet and web browsers. Apart from education, the system for remote access and control via the internet is also applicable to real industrial mechatronics systems.

\section{Acknowledgement}

This paper was realized as a part of the projects TR 35005 and III 43007, financed by the Ministry of Education and Science of the Republic of Serbia for the period 2011-2014. 


\section{References}

[1] P. Tóth: Learning Strategies and Styles in Vocational Education, Acta Polytechnica Hungarica, Vol. 9, No. 3, pp. 195-216, 2012

[2] R. H. Bishop: The Mechatronics Handbook, The University of Texas at Austin, Austin, Texas, 2002

[3] S. Aleksandrov, R. Aleksandrov, P. Simić: Usage of Modern Didactic System in Education in Area of Mechatronic Enginering, Proceedings of the $6^{\text {th }}$ International Symposium of Technology, Informatics and Education for Learning and Knowledge Society, Čačak, Serbia, 3-5 June, pp. 607-612, 2011

[4] S. Aleksandrov, S. Čajetinac, D. Šešlija: Didactic System Festo-MPSSorting Station and its Application in Education in the Field of Mechatronics, Proceedings of $10^{\text {th }}$ International Conference Research and Development in Mechanical Industy - RaDMI 2010, Donji Milanovac, Serbia, 16-19 September, pp. 549-553, 2010

[5] K. Yeung, S. Chow: The Modular Production System (MPS): an Alternate Approach for Control Technology in Design and Technology, In: IDATER 98 Loughborough University, Hong Kong SAR

[6] R.-E. Precup, S. Preitl, M. B. Radac, E. M. Petriu, C. A. Dragos, J. K. Tar: Experiment-based Teaching in Advanced Control Engineering, IEEE Transactions on Education, Vol. 54, No. 3, pp. 345-355, 2011

[7] W. H. Liao, S. C. Wang, Y. H. Liu: Generalized Simulation Model for a Switched-Mode Power Supply Design Course Using MATLAB/ SIMULINK, IEEE Transactions on Education, Vol. 55, No. 1, pp. 36-47, 2012

[8] D. G. Lamar, P. F. Miaja, M. Arias, A. Rodriguez, M. Rodríguez, A. Vázquez, M. M. Hernando, J. Sebastián: Experiences in the Application of Project-based Learning in a Switching-Mode Power Supplies Course, IEEE Transactions on Education, Vol. 55, No. 1, pp. 69-77, 2012

[9] F. W. Bruns, H. H. Erbe, M. Faust: Engineering Future Laboratories, In: Marvel - A Leonardo da Vinci Pilot Project- Mechatronics Training in Real and Virtual Environments, Bremen, 2005

[10] D. Muller: Designing Learning Spaces for Mechatronics, In: Marvel - A Leonardo da Vinci Pilot Project- Mechatronics Training in Real and Virtual Environments, Bremen, 2005

[11] C. E. Pereira, S. Paladini, F. M. Schaf: Control and Automation Engineering Education: Combinig Physical, Remote and Virtual Labs, Proceedings of the $9^{\text {th }}$ International Multi-Conference on Systems, Signals and Devices - SSD 2012, Chemnits, Germany, 20-23 March, pp. 1-10, 2012 
[12] R. C. Hsu, W. C. Liu, Project-based Learning as a Pedagogical Tool for Embedded System Education, In Proceedings of $3^{\text {rd }}$ International Conference on Information Technology: Research and Education, ITRE 2005, Hsinchu, Taiwan, 27-30 June, pp. 362-366, 2005

[13] I. G. Pop, V. Matiec: Transdisciplinary Approach of the Mechatronics in the Knowledge-based Society, Advances in Mechatronics, H. MartinezAlfaro (Ed.), InTech, 2011

[14] L. Izsó, P. Tóth: Applying Web-Mining Methods for Analysis of Student Behaviour in VLE courses, Acta Polytechnica Hungarica, Vol. 5, No. 4, pp. 79-92, 2008

[15] E. Lindsay, M. Good: The Impact of Audiovisual Feedback on the Learning Outcomes of a Remote and Virtual Laboratory Class, IEEE Transactions on Education, Vol. 52, No. 4, 2009

[16] C. Buiu: Design and Evaluation of an Integrated Online Motion Control Training Package, IEEE Transactions on Education, Vol. 52, No. 3, pp. 385-393, 2009

[17] E. Montero, M. J. Gonzalez: Student Engagement in a Structured Problembased Approach to Learning: A First-Year Electronic Engineering Study Module on Heat Transfer, IEEE Transactions on Education, Vol. 52, No. 2, pp. 214-221, 2009

[18] Festo, “The Modular Production System - User’s Manual”, 2013.

Available: http://www.festo-didactic.com

[19] I. Grout, J. Walsh: Microelectronic Circuit Test Engineering Laboratories with Programmable Logic, International Journal of Electrical Engineering Education, Vol. 41, No. 4, pp. 313-327, 2004

[20] J. J. Blakley, D. A. Irvine: Teaching Programmable Logic Controllers Using Multimedia-based Courseware, International Journal of Electrical Engineering Education, Vol. 37, No. 4, pp. 305-345, 2000

[21] L. Cheded, M. Al-Mulla: Control of a Four-Level Elevator System Using a Programmable Logic Controller, International Journal of Electrical Engineering Education, Vol. 39, No. 2, pp. 110-117, 2002

[22] M. Račić, J. Jovanović: Comparative Analysis of Mechanical and Mechatronic Design, Proceedings of the $9^{\text {th }}$ International Conference Research and Development in Mechanical Industy - RaDMI 2009, Vrnjačka Banja, Serbia, 16-19 September, pp. 332-339, 2009

[23] S. H. Pulko, S. Parikh: Teaching Soft Skills to Engineers, International Journal of Electrical Engineering Education, Vol. 40, No. 4, pp 243-254, 2003 